\begin{tabular}{|c|c|c|c|c|c|c|}
\hline \multirow{4}{*}{ Impact Factor: } & ISRA (India) & $=3.117$ & SIS (USA) & $=0.912$ & ICV (Poland) & $=6.630$ \\
\hline & ISI (Dubai, UAE & $=0.829$ & РИНЦ (Russia & $=0.156$ & PIF (India) & $=1.940$ \\
\hline & GIF (Australia) & $=0.564$ & ESJI (KZ) & $=8.716$ & IBI (India) & $=4.260$ \\
\hline & JIF & $=1.500$ & SJIF (Morocco & $=\mathbf{5 . 6 6 7}$ & OAJI (USA) & $=0.350$ \\
\hline
\end{tabular}

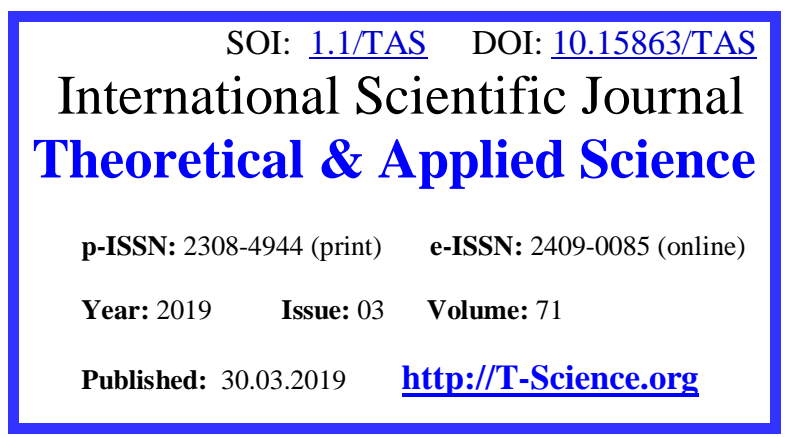

UDC 616.43; 616.36-002.2

\section{International Scientific Journal}

p-ISSN: 2308-4944 (print) e-ISSN: 2409-0085 (online)

Published: $30.03 .2019 \quad \underline{\text { http://T-Science.org }}$

\section{SECTION 20. Medicine.}

QR - Issue

QR - Article
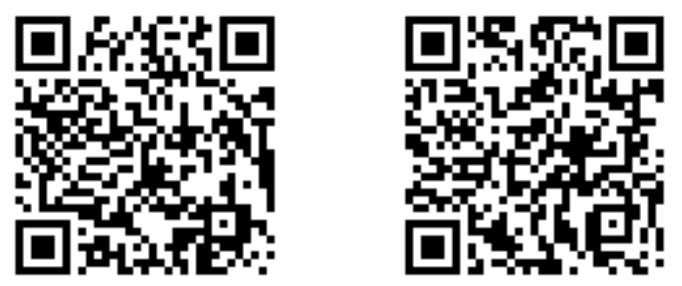

Arzu Yeskuatovna Mamutova Candidate of Medical Sciences, acting associate professor Propedeutics and Internal disease department International Kazakh-Turkish University by name

Yassavi, Kazakhstan arzu.mamutova@mail.ru

Ikilas Suyndikovich Moldaliyev Professor, Doctor of Medical Sciences

Preventive Medicine department International Kazakh-Turkish University by name

Yassavi, Kazakhstan mikilas@mail.ru

Sarviniso Islamovna Ibragimova Master of medical science 1 -year $\mathrm{PhD}$ student International Kazakh-Turkish University by name Yassavi, Kazakhstan sarvinsa@mail.ru

\title{
PREDIABETES AND VIRAL HEPATITIS
}

Abstract: This article reviewed the literature on the study of the correlation between pre-diabetes and viral hepatitis $C$, as well as some aspects of the pathophysiological mechanisms of pre-diabetes in viral hepatitis.

Key words: prediabetes, diabetes mellitus, viral hepatitis, insulin resistance.

Language: Russian

Citation: Mamutova, A. Y., Moldaliyev, I. S., \& Ibragimova, S. I. (2019). Prediabetes and viral hepatitis. ISJ Theoretical \& Applied Science, 03 (71), 489-492.

Soi: http://s-o-i.org/1.1/TAS-03-71-46 Doi: crossef https://dx.doi.org/10.15863/TAS.2019.03.71.46

\section{ПРЕДИАБЕТ И ВИРУСНЫЙ ГЕПАТИТ}

Аннотация: В данной статье проведен обзор литературы по изучению корреляции между предиабетом и вирусным гепатитом С, а также приведены некоторые аспекты патофизиологических механизмов развития предиабета при вирусном гепатите.

Ключевые слова: предиабет, сахарный диабет, вирусный гепатит, инсулинорезистентность.

\section{Introduction}

Учитывая, что предиабет является потенциально обратимым состоянием, раннее распознавание и вмешательство могут предотвратить трансформацию предиабета в сахарный диабет 2 типа (СД) и связанных с ним осложнений. Предиабет включает в себя нарушенную гликемию натощак (НГН) и/или нарушенную толерантность к глюкозе (НТГ), которые в конечном итоге прогрессируют в СД у большинства пациентов. Важно отметить, что в основе НГН и НТГ лежат различные патофизиологические механизмы, в зависимости от вида инсулинорезистентности. Периферическая инсулинорезистентность, которая имеет место в мышечных и жировых клетках, по-видимому, играет большую роль в механизме НТГ, тогда как НГН ассоциируется преимущественно с инсулинорезистентностью в печени. Воспаление печени, вызванное вирусным 


\begin{tabular}{|c|c|c|c|c|c|c|}
\hline \multirow{4}{*}{ Impact Factor: } & ISRA (India) & $=\mathbf{3 . 1 1 7}$ & SIS (USA) & $=0.912$ & ICV (Poland) & $=6.630$ \\
\hline & ISI (Dubai, UAE & $=0.829$ & РИНЦ (Russia & $=0.156$ & PIF (India) & $=1.940$ \\
\hline & GIF (Australia) & $=0.564$ & ESJI (KZ) & $=8.716$ & IBI (India) & $=4.260$ \\
\hline & JIF & $=1.500$ & SJIF (Morocco & $=5.667$ & OAJI (USA) & $=0.350$ \\
\hline
\end{tabular}

гепатитом, может, в свою очередь, играть роль в нарушении метаболизма глюкозы вследствие его потенциального воздействия на развитие инсулинорезистентности в печени [1].

\section{Materials and Methods}

Вирус гепатита С (ВГС) является основной причиной хронических заболеваний печени и гепатоцеллюлярной карциномы, наряду с этим, эпидемиологические исследования показали сильную связь между ВГС и СД. НГН и НТГ являются проявлениями ранних нарушений гомеостаза глюкозы, которые предшествуют диабету. Учитывая неблагоприятные последствия нарушений метаболизма глюкозы, важно понимать механизмы развития предиабетического состояния, в том числе инсулинорезистентности. Надлежащий скрининг и лечение предиабета особенно важны в случае наличие ВГС, так как было показано, что нарушение метаболизма глюкозы способствует фиброзу печени, снижает чувствительность к противовирусной терапии и приводит к неблагоприятным результатам после трансплантации печени [2].
Как ВГС, так и диабет являются распространенными патологиями. Вскоре после обнаружения ВГС в 1989 году, была выявлена связь между ВГС с диабетом 2 типа [3]. Впервые об ассоциации между СД и ВГС было сообщено в 1994 г. Эллисоном и соавторами, который заметил, что распространенность СД была значительно выше у пациентов с циррозом, связанным с ВГС. Частота встречаемости серопозитивного ВГС в популяции пациентов с СД варьировала от 1,8\% до 12,1\%, наряду с этим, было выявлено, что СД развивается у 14,5-33,0\% пациентов с ВГС [4].

Точные механизмы сложного действия вирусных факторов, которые приводят к развитию нарушенного гликемического контроля у пациентов с ВГС, недостаточно изучены. Некоторые исследования предполагают, что ВГС изменяет гомеостаз глюкозы, вследствие генотипоспецифичности, а также наличия стеатоза печени. Так же известно, что воспаление печени ассоцируется с НГН [5].

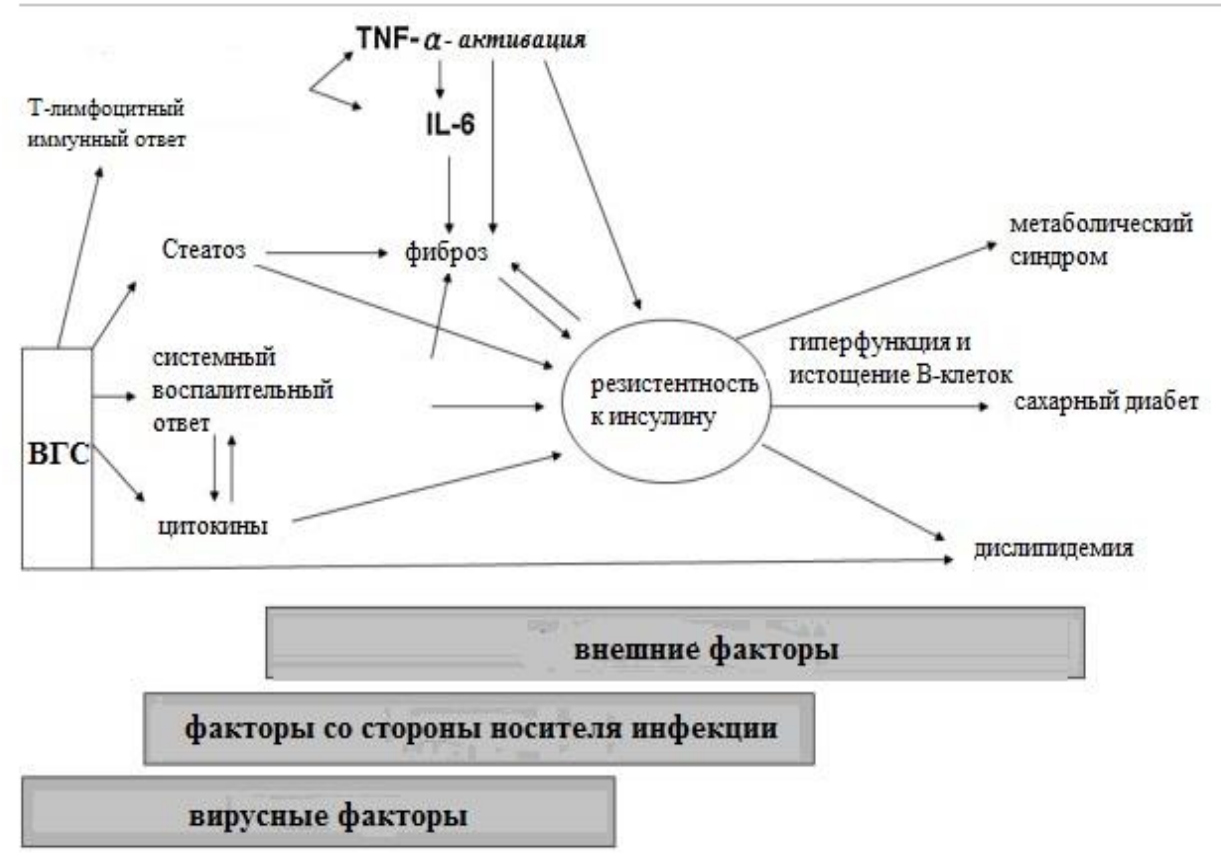

Рисунок 1. Механизм развития инсулинорезистентности при ВГС [4].

Huang J.F. и соавторы представили возможный механизм, приводящий к развитию инсулинорезистентности и последующим нарушениям обмена веществ при ВГС. ВГС запускает иммунный каскад, опосредованный лимфоцитами, которые усиливают активацию фактора некроза опухоли (TNF- $\alpha)$ и повышение уровня интерлейкина (IL-6). ВГС напрямую приводит к стеатозу, также может вызывать системный воспалительный и цитокиновый ответ, которые являются потенциально фиброгенными факторами. Все эти изменения в свою очередь увеличивают риск развития инсулинорезистентности, которая играет 


\begin{tabular}{|c|c|c|c|c|c|c|}
\hline \multirow{4}{*}{ Impact Factor: } & ISRA (India) & $=3.117$ & SIS (USA) & $=0.912$ & ICV (Poland) & $=6.630$ \\
\hline & ISI (Dubai, UAE & $=0.829$ & РИНЦ (Russia) & $=0.156$ & PIF (India) & $=1.940$ \\
\hline & GIF (Australia) & $=0.564$ & ESJI (KZ) & $=8.716$ & IBI (India) & $=4.260$ \\
\hline & JIF & $=1.500$ & SJIF (Morocco & $=5.667$ & OAJI (USA) & $=0.350$ \\
\hline
\end{tabular}

ключевую роль в развитии последующих метаболических нарушений. В отношении развития предиабета, гиперфункция бета-клеток поджелудочной железы, направленная на поддержание гомеостаза глюкозы и повышение уровня инсулина в сыворотке крови, являются главной особенностью возникновения данного состояния. Гиперфункция и истощение бетаклеток поджелудочной железы развиваются на начальных стадиях ВГС. Факторов со стороны носителя инфекции (генетическая предрасположенность, мужской пол, индекс массы тела и др.), факторы окружающей среды (сидячий образ жизни, диета и др.) и вирусные факторы (генотип, вирусная нагрузка) также вовлечены в этот сложный механизм [4]. Таким образом, механизм, с помощью которого ВГС может вызывать гипергликемию, связан с инсулинорезистентностью и потенциальными дефектами в сигнальных путях инсулина. Проведенные исследования показали более высокую распространенность инсулинорезистентности при ВГС по сравнению с инфекцией вирусом гепатита $\mathrm{B}$ и другими причинами заболеваний печени [6].

Литературные данные связывают развитие предиабета и диабета 2 типа изменениями функции ферментов печени. Неблагоприятные значения аланинаминотрансферазы (АЛТ) и гамма-глютамилтранспептитазы (ГГТ) были отмечены как риск последующего развития предиабета и СД [7]. Кроме того, метаанализ проведенный Fraser A., и соавторами предположил, что ГГТ может быть лучшим предиктором диабета, чем АЛТ. Повышение уровня как ГГТ, так и АЛТ оказалось сильным маркером инсулинорезистентности, независимо от абдоминального ожирения [8]. Несмотря на то, что связь между ВГС и гипергликемией установлена во многих исследованиях, имеются работы где не обнаруживается ассоциация между этими двумя переменными [9].

\section{Conclusion}

Таким образом, в научной литературе имеются данные о сделанных важных открытиях в понимании тесной взаимосвязи между ВГС и гомеостазом глюкозы. Как поперечные, так и продольные исследования показали, что инфицирование ВГС связано с повышенным риском развития резистентности к инсулину и диабета 2 типа. Взаимодействие между ВГС и метаболизмом глюкозы имеет значительные клинические последствия. Резистентность к инсулину и диабет 2 типа не только ускоряют гистологическое и клиническое прогрессирование хронического гепатита C, но также снижают вирусологический ответ на терапию противовирусными препаратами [10].

Исходя из этого, понимание механизмов, лежащих в основе нарушений метаболизма глюкозы, связанных с ВГС, представляет первостепенный интерес для улучшения клинического ведения хронического гепатита С.

\section{References:}

1. Burman, B. E., Bacchetti, P., Ayala, C. E., Gelman, N., Melgar, J., \& Khalili, M. (n.d.). Liver inflammation is a risk factor for prediabetes in at-risk latinos with and without hepatitis C infection. Liver Int., 35(1), 101-107.

2. Mukhtar, N. A., Ayala, C., Maher, J. J., \& Khalili, M. (2012). Assessment of Factors Associated with Pre-diabetes in HCV Infection Including Direct and Dynamic Measurements of Insulin Action. J Viral Hepat, 19(7), 480-487.

3. Ruhl, C. E., Menke, A., Cowie, C. C., Everhart, J. E. (2014). The Relationship of Hepatitis C Virus Infection with Diabetes in the United States Population. Hepatology, 60(4), 11391149.

4. Huang, J. F., Yu, M. L., Dai, C. Y., \& Chuang, W. L. (2013). Glucose abnormalities in hepatitis $\mathrm{C}$ virus infection. Kaohsiung $\mathrm{J} \mathrm{Med}$ Sci., 29(2), 61-68. https://www.ncbi.nlm.nih.gov/pubmed/2334780 $\underline{6}$

5. Hsu, C. S., et al. (2008, Feb.). High hepatitis C viral load is associated with insulin resistance in patients with chronic hepatitis C. Liver Int., 28(2), 271-277.

6. Mukhtar, N. A., Ayala, C., Maher, J. J., \& Khalili, M. (2012). Assessment of factors associated with pre-diabetes in HCV infection including direct and dynamic measurements of insulin action. Journal of viral hepatitis, 19, 480-487.

7. Nguyen, Q. M., et al. (2011). Elevated liver function enzymes are related to the development of prediabetes and type 2 diabetes in younger 


\begin{tabular}{|c|c|c|c|c|c|c|}
\hline \multirow{4}{*}{ Impact Factor: } & ISRA (India) & $=3.117$ & SIS (USA) & $=0.912$ & ICV (Poland) & $=6.630$ \\
\hline & ISI (Dubai, UAE & $=0.829$ & РИНЦ (Russia & $=0.156$ & PIF (India) & $=1.940$ \\
\hline & GIF (Australia) & $=0.564$ & ESJI (KZ) & $=8.716$ & IBI (India) & $=4.260$ \\
\hline & JIF & $=1.500$ & SJIF (Morocco & $=5.667$ & OAJI (USA) & $=0.350$ \\
\hline
\end{tabular}

adults: the Bogalusa Heart Study. Diabetes care, 34, 2603-2607.

8. Bonnet, F., et al. (2011). Liver enzymes are associated with hepatic insulin resistance, insulin secretion, and glucagon concentration in healthy men and women. Diabetes, 60, 16601667.

9. Stepanova, M., Lam, B., Younossi, Y., Srishord, M. K., \& Younossi, Z. M. (2012, May). Association of hepatitis $\mathrm{C}$ with insulin resistance and type 2 diabetes in US general population: the impact of the epidemic of obesity. J Viral Hepat, 19(5), 341-345.

10. Kaddai, V., \& Negro, F. (2011). Current understanding of insulin resistance in hepatitis C. Expert Rev Gastroenterol Hepatol, 5(4), 503-516. https://www.ncbi.nlm.nih.gov/pubmed/2178089 7I 